\title{
ENSINO UNIVERSITÁRIO DE EMPREENDEDORISMO SOCIAL: UMA REVISÃO DA LITERATURA DE 2013 A 2018
}

Junio Braga ${ }^{1}$

Gardenia Abbad $^{1}$

${ }^{1}$ Universidade de Brasília 


\section{ENSINO UNIVERSITÁRIO DE EMPREENDEDORISMO SOCIAL: UMA REVISÃO DA LITERATURA DE 2013 A 2018}

Com o intuito de possibilitar o acesso a produtos e a serviços para a parte mais vulnerável da população e com o desejo de contrabalançar as desigualdades no mundo, surge o empreendedorismo social. Diante desse movimento que vem ganhando relevância, esta pesquisa buscou analisar a literatura sobre o campo do ensino universitário de empreendedorismo social, de 2013 a 2018, no Portal de Periódicos Capes, utilizando protocolo proposto por Cronin, Ryan e Coughlan (2008) e os descritores "social entrepreneurship" and "students. Essa busca resultou em 987 artigos que tiveram os títulos, resumos e a introdução lidos, com vistas à verificação da aderência aos temas proposto nessa revisão. Foram excluídos todos os artigos que tratavam do empreendedorismo social em contextos não universitários ou publicados em língua diferente da portuguesa, da inglesa e da espanhola. Foram selecionados para análise 36 artigos que tratavam de empreendedorismo social no contexto educacional de nível superior.

Palavras-chave: Revisão de literatura. Empreendedorismo Social. Educação.

\section{Introdução}

No Brasil, cerca 54,8 milhões de pessoas vivem na pobreza, segundo dados do Instituto Brasileiro de Geografia e Estatística (2017), e parte dessa população tem dificuldade de acesso à educação, à saúde e à moradia de qualidade, sendo estes direitos fundamentais previstos no artigo $5^{\circ}$ da Constituição Federal. Amartya Sen (1999) diz que a pobreza não é você ter uma renda abaixo de um valor preestabelecido, é a privação de necessidades básicas, como aquelas garantidas na Carta Magna. Nesse contexto de possibilitar o acesso a produtos e a serviços para a parte mais vulnerável da população e com o desejo de contrabalançar as desigualdades no mundo, surge o empreendedorismo social.

No entanto, sobre o conceito de empreendedorismo social - ES não existe, na literatura científica, uma definição consensualmente aceita pelos pesquisadores. As principais definições encontradas nessa revisão da literatura relacionam ES com um dos seguintes aspectos: está ligado a um desejo pessoal, tem o intuito de resolver um problema social, utiliza-se de estratégias de mercado, é inovador, cria valor social, preocupa-se com a sustentabilidade econômica, financeira, ambiental e social, o lucro pode ou não se reinvestido na própria organização, tem impacto social positivo, é agente de mudança e é voltado para a população mais desfavorecida. Além disso, as definições trazem o envolvimento pessoal do empreendedor social, sendo este, um dos fatores chaves para se compreender esse tipo de empreendedorismo.

No intuito de compreender esse movimento este trabalho buscou analisar a produção dos conhecimentos sobre Ensino Universitário de Empreendedorismo Social e a metodologia principal para isso baseou-se no protocolo proposto por Cronin, Ryan e Coughlan (2008) de revisão sistemática da literatura. A revisão abrangeu artigos científicos publicados em revistas qualificadas, localizados em bases de dados do Portal de Periódicos Capes. A pesquisa adotou como pressupostos a formulação de objetivos específicos e o planejamento das buscas para formar o corpo de conhecimento do tema de interesse, o Ensino de Empreendedorismo Social. 
Segundo Cook, Mulrow e Haynes (1997), revisões sistemáticas são investigações científicas com métodos prévios de planejamento e a montagem de estudos originais sobre um determinado o assunto. O levantamento do corpo de conhecimentos por meio de revisões sistemáticas implica, pois, em formar um referencial consistente de uma amostra de publicações, visando identificar tendências e encontrar lacunas em pesquisas, as quais possam ser mais bem exploradas posteriormente. Nas revisões sistemáticas os "sujeitos" da investigação são os estudos primários (unidades de análise) selecionados por meio de método sistemático e pré-definido (Cordeiro, Oliveira, \& Guimarães, 2007).

\section{Desenvolvimento}

O primeiro passo da revisão da literatura sobre ensino universitário de empreendedorismo social foi à busca de artigos científicos por meio de palavras-chave relacionadas ao campo. Na primeira busca, foi utilizado o descritor "social entrepreneurship education". Esse descritor resultou na localização de 49 artigos científicos revisados por pares e publicados em revistas qualificadas da área, no período compreendido entre 2013 a 2018. Após a leitura do título e do resumo de todos eles, foram excluídos os textos que tratavam do empreendedorismo social fora dos contextos universitários. Foram selecionados apenas 17 trabalhos que tratavam do assunto no contex to de ensino universitário.

Uma nova busca foi realizada visando associar o tema principal ao público - alvo de interesse, os estudantes universitários. Essa busca de artigos utilizou como descritores "social entrepreneurship" and "students" e foi realizada no Portal de Periódicos Capes, levando em conta publicações ocorridas no mesmo período de tempo, entre 2013 e 2018. Essa etapa resultou na localização de 987 artigos. Posteriormente utilizou-se o critério objetivo da pesquisa para a seleção e o refinamento, quais sejam: (1) artigos que tratassem do tema de empreendedorismo social no contexto educacional (ensino, professor, universidade e/ou estudante) e (2) data de publicação para cumprir o objetivo desse trabalho que é analisar as publicações dos últimos cinco anos.

Nesta segunda busca os 987 artigos tiveram os títulos, resumos e a introdução lidos, com vistas à verificação da aderência aos temas. Foram excluídos todos os artigos que tratavam do empreendedorismo em contextos não universitários ou publicados em língua diferente da portuguesa, da inglesa e da espanhola. Foram selecionados para análise apenas 36 artigos que tratavam de empreendedorismo social no contexto educacional de nível superior (graduação e pós-graduação).

Além dessas, foi realizada uma busca de artigos publicados em revistas de língua portuguesa no Portal de Periódico, utilizando o mesmo período de tempo das buscas anteriores e os mesmos descritores, porém redigidos em língua portuguesa ("empreendedorismo social" e estudantes). Essa etapa da pesquisa resultou na localização de 23 artigos. Apenas um artigo foi selecionado, pois relata estudo sobre empreendedorismo social em contexto universitário.

A Tabela 1 mostra o número de artigos encontrados, bem como as respectivas palavras-chave em cada plataforma de busca.

Tabela 1

Número de artigos localizados no Portal de periódicos CAPE, selecionados de acordo com os descritores 


\begin{tabular}{|c|c|c|c|}
\hline Palavras-chave & $\begin{array}{l}\mathrm{N}^{0} \text { de artigos } \\
\text { identificados }\end{array}$ & $\begin{array}{l}\mathrm{N}^{\mathrm{o}} \text { de artigos selecionados após a } \\
\text { leitura do titulo e resumo }\end{array}$ & Aproveitamento (\%) \\
\hline $\begin{array}{l}\text { "social entrepreneurship } \\
\text { education" }\end{array}$ & 56 & 17 & $30 \%$ \\
\hline $\begin{array}{l}\text { "social entrepreneurship" } \\
\text { and } \\
\text { students }\end{array}$ & 987 & 75 & $7,5 \%$ \\
\hline $\begin{array}{l}\text { "empreendedorismo social" } \\
\text { e estudantes }\end{array}$ & 23 & 1 & $4,3 \%$ \\
\hline Total & 1.066 & 93 & - \\
\hline
\end{tabular}

Fonte: Elaborada pelo autor.

\section{Análise e síntese dos resultados}

Os dados foram tabulados em uma planilha eletrônica e classificados de acordo com os seguintes aspectos: referência padrão American Psychological Association (APA), título, autores, resumo, palavras-chave, periódico, ano de publicação, país do estudo, objetivo, hipóteses, tipo (teórico e teórico-empírico), termos utilizados, definição do campo, modelo teórico, natureza da pesquisa (descritiva, explicativa e exploratória), público, abordagem da pesquisa (qualitativa, quantitativa e mista quali-quanti), origem dos dados (primários, secundários e mista), delineamento (experimental, quase-experimental, correlacional e sem delineamento), nível de análise (individual, grupo e organizacional), recorte temporal (transversal e longitudinal), método (estudo de caso, etnografia, experimento, quaseexperimento, survey e levantamento de opinião), amostragem quantitativa (probabilística ou não-probabilística) e qualitativa (rígida, flexível ou teórica), perfil da amostra, variáveis estudadas, instrumentos/procedimentos de coleta (questionário, análise documental, roteiro de entrevistas e grupo de foco), coleta (meio eletrônico e presencial), técnicas de análise de dados (estatísticas descritiva ou inferenciais, análise de conteúdo e análise de discurso), resultados, limitações, recomendações, justificativa, agenda de pesquisa e comentários gerais dos pesquisadores.

Quanto à abordagem, os estudos podem ser classificados como quantitativos, qualitativos e mistos. Os estudos quantitativos, segundo Creswell (2007), são geralmente concentrados na produção de conhecimento científico a partir da testagem de relações de determinadas variáveis, utilizando-se de instrumentos que geram dados estatísticos. Já os estudos qualitativos adotam fundamentos construtivistas e tendem a utilizar-se de estratégias de pesquisas que permitam a análise em profundidade do contexto pesquisado. A abordagem mista utiliza os dois meios de investigação, simultânea ou sequencialmente.

Sobre o recorte temporal, os artigos classificados como transversais, se caracterizam por observar um objeto/fenômeno em um único momento. (Hair, Babin, Money, \& Samouel, 2003).

Quanto aos métodos, face à variedade de opções resultantes da multidisciplinaridade de quadros teórico-analíticos presentes na Administração, foram consideradas as seguintes classificações: levantamento de opiniões/survey - estudos que têm como característica a reunião de dados e informações por meio de perguntas diretamente às pessoas (Fowler, 2011); estudo de caso - investigações em profundidade caracterizada pela multiplicidade 
metodológica (Yin, 2002) e quase-experimento/experimento (Shadish, Cook e Campbell, 2002) - um experimento no qual as unidades (estudadas - isto é, pessoas, grupos, instituições etc.) podem ou não serem distribuídas às condições (experimentais e controle) aleatoriamente.

As técnicas de amostragem foram agrupadas, segundo Hair et al. (2003), em censitárias (foco na população/amostragem inexistente), probabilísticas (foco em estratos populacionais estatisticamente determinados) ou não-probabilísticas (foco em pessoas, relatos, imagens e situações selecionadas sem nenhuma aplicação de critérios estatísticos de representatividade). Enquanto os estudos censitários e probabilísticos reúnem iniciativas de pesquisa tipicamente quantitativas concentradas na validade externa, os que fazem uso de técnicas não probabilísticas abarcam tanto pesquisas quantitativas (por exemplo, acessibilidade e intencional) como qualitativas (por exemplo, por saturação teórica e rígida), não se preocupando com a fidedignidade das conclusões tecidas (validade interna) e suas generalizações (validade externa).

Os artigos foram classificados também a partir dos instrumentos de registro de dados e informações: questionários, roteiros para condução de entrevistas, roteiro de observações e roteiro para condução de grupos de foco. Por fim, concernente às técnicas analíticas empregadas, considerou-se as seguintes classificações: estatísticas descritivas, estatísticas inferenciais, análise de conteúdo, análise do discurso e análise combinada, sendo a última empregada por meio de técnicas de natureza qualitativa e quantitativa.

\section{Resultados da Análise da produção de conhecimentos}

Esta seção apresenta os principais resultados encontrados na revisão sistemática da literatura sobre o tema de ensino em empreendedorismo social. Primeiramente, serão apresentadas as informações gerais sobre as publicações. Na sequência, serão analisados os aspectos procedimentais e metodológicos utilizados nos artigos avaliados. Por fim, serão descritos os principais conteúdos dos artigos, resultados encontrados e as agendas de pesquisas.

\section{Informações gerais sobre os artigos}

A distribuição temporal das 37 publicações analisadas pode ser visualizada na Figura 1. Em todo o período analisado, observa-se um crescimento no número de publicações. Porém, o número de artigo dobrou no ano de 2017 e 2018. A Figura 1 mostra a quantidade de artigos por ano de publicação no intervalo de tempo pesquisado.

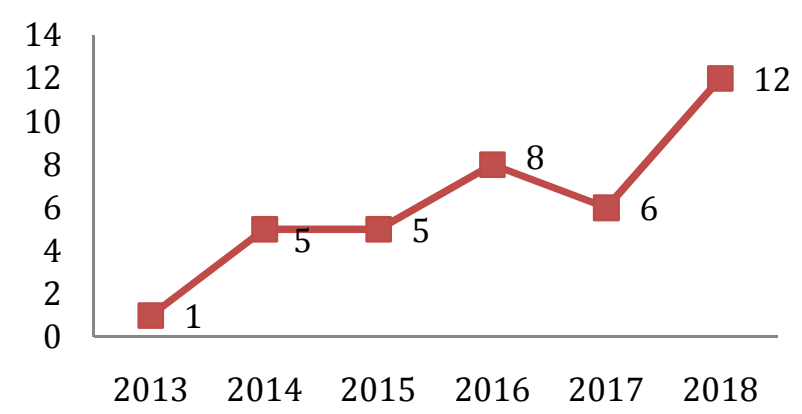

Figura 1. Número de publicações

Fonte: Elaborado pelo autor. 
A partir do conjunto de palavras-chave utilizadas nos descritores dos artigos, observou-se que o termo mais frequente utilizado nos artigos foi "social entrepreneurship" com 13 manifestações, seguido pelos descritores "creativity", "entrepreneurship" e "social", com três ocorrências cada e por fim "attitude", "emotional intelligence", "entrepreneurship education", "experiential learning", "learning-by-doing", "moral obligation", "motivation", e "social business", com duas aparições. Outras 68 palavras-chaves foram encontradas com uma frequência apenas.

As revistas que mais publicaram artigos encontrados nessa revisão foram; "Entrepreneurial Business and Economics Review", "Innovations in Educationand Teaching International", "Journal of Social Work Education" "Social Enterprise Journal", com duas publicações cada uma. No entanto, observa-se uma grande heterogeneidade de revistas internacionais que tem publicado com o tema, uma vez que foram encontradas 27 outras revistas com publicação única.

Os principais autores na área têm sido Kai Hockerts e Jyoti Tikoria, com três publicações cada um, sendo o Kai Hockerts um autor bastante citado também nas pesquisas aqui encontradas, seguido de Alison Rieple, Anil K. Bhat, Chaoyun Liang, Ching Yin Ip, Huei-Ching Liu e Shih-Chia $\mathrm{Wu}$, com dois artigos publicados no período abrangido por esta pesquisa. Porém, foram encontrados outros 73 autores/co-autores com uma única publicação.

Observa-se que oito pesquisas foram realizadas em mais de um país: EUA, Reino Unido, Irlanda e Austrália (Thomsen, Muurlink, \& Best, 2018), Taiwan e Hong Kong (Ip, Liang, Wu, Law, \& Liu, 2018; Hsu \& Wang, 2018), EUA e África do Sul (Bacq \& Alt, 2018), EUA e Alemanha (Mueller, Brahm \& Neck, 2015), Filipinas e Indonésia (Lacap, Mulyaningsih, \& Ramadani, 2018), Áustria, Bósnia, Croácia, Eslovênia e antiga República da Iugoslávia da Macedônia (Kedmenec, Rebernik, \& Tominc, 2016), Lituânia e Polônia (Greblikaite, 2016). As demais pesquisas foram realizadas em apenas um país. Cabe ressaltar que os Estados Unidos tem sido o responsável pelo maior número publicação de artigos (sete), seguido da Índia (três). Espanha, Malásia e Reino Unido seguem todos com duas publicações.

\section{Aspectos procedimentais e metodológicos dos estudos}

As pesquisas foram delineadas a partir das seguintes categorias: tipo, abordagem, natureza, recorte, origem dos dados e nível de análise. Vale ressaltar que, em alguns casos, os dados constantes dos textos analisados não permitiram a classificação, em razão da omissão de informações ou imprecisão do tex to no que se refere a esses aspectos. Os estudos teóricos foram apenas contabilizados, diferentemente dos teórico-empíricos cujas tipificações metodológicas foram detalhadas.

Predominam, na literatura internacional sobre ensino em empreendedorismo social, estudos teórico-empíricos $(81,1 \%)$. Foram encontrados poucos artigos teóricos sobre o tema $(18,9 \%)$. Grande parte dos trabalhos assumiu uma abordagem quantitativa de campo $(73,3 \%)$, seguida de estudos de abordagem qualitativa $(16,7 \%)$ e apenas três trabalhos de delineamento misto (10\%). A natureza desses estudos ainda é predominantemente descritiva $(53,4 \%)$, seguida de explicativa $(23,3 \%)$ e exploratória $(23,3 \%)$. Todos os estudos tiveram recorte temporal transversal $(100 \%)$ e dentre esses apenas um com duas medidas repetidas. A origem dos dados é primária na quase totalidade dos estudos $(93,3 \%)$, sendo que apenas dois artigos utilizaram fontes primárias e secundárias de dados $(6,7 \%)$ e nenhum artigo utilizou somente 
dados secundários. 14 estudos apresentam delineamento (46,7\%), sendo 12 (40\%) correlacional e dois $(6,7 \%)$ quase-experimento.

Quanto ao nível de análise das pesquisas, predominam estudos que analisam o nível do indivíduo (93,4\%). Apenas um estudo analisou o ensino de empreendedorismo social no nível organizacional (3,3\%), considerando os dados de um programa (concurso) de empreendedorismo e outro no nível de equipe/grupo (3,3\%). Os focos principais das pesquisas são apresentados na Tabela 3 .

Tabela 3

Contexto dos 30 artigos teórico-empíricos analisados

\begin{tabular}{lccl}
\hline Contexto & $\mathbf{N}^{\mathbf{0}}$ & \% & Autor(es) \\
\hline & & & Chang, J., Benamraoui, A., \& Rieple, A. (2014) \\
& & & $\begin{array}{l}\text { Yann Ching Chang, J., Benamraoui, A., \& Rieple, A. } \\
\text { (2014). }\end{array}$ \\
$\begin{array}{l}\text { Disciplinas presenciais de } \\
\text { empreendedorismo social }\end{array}$ & 4 & $\begin{array}{l}\text { Mueller, S., Brahm, T., \& Neck, H. (2015) } \\
\text { Bacq, S., \& Alt, E. (2018) }\end{array}$
\end{tabular}

Disciplina presencial e virtual de empreendedorismo social

$13,3 \quad$ Hockerts, K. (2018)

Professores com experiência na área de empreendedorismo/empreendedorism o social

Professores em formação

Programa de serviço social e administração

Programa para estudantes universitários

Competição de empreendedorismo social

Participantes de um projeto de empreendedorismo social

Estudantes universitários

Estudantes nacionais e internacionais

Estudantes de engenharia
13,3 Thomsen, B., Muurlink, O., \& Best, T. (2018)

$1 \quad 3,3 \quad$ Konakll, T. (2015).

$1 \quad 3,3 \quad$ Archibald, P., Muhammad, O., \& Estreet, A. (2016)

13 Othman, N., \& Ab Wahid, H. (2014)

13,3 Huster, K., Petrillo, C., O’Malley, G., Glassman, D., Rush, J., \& Wasserheit, J. (2017)

$1 \quad 3,3 \quad$ Sabbaghi, O., \& Cavanagh, SJ, G. F. (2018)

Lacap, J. P. G., Mulyaningsih, H. D., \& Ramadani, V.(2018)

Hsu, C. Y., \& Wang, S. M. (2018)

Ip, C. Y., Wu, S. C., Liu, H. C., \& Liang, C. (2018)

Ip, C. Y., Liang, C., Wu, S. C., Law, K. M. Y., \& Liu, H. C. (2018)

3,3 Ashour, S. (2016)

Tiwari, P., Bhat, A. K., \& Tikoria, J. (2017a)

Tiwari, P., Bhat, A. K., \& Tikoria, J. (2017b)

Tiwari, P., Bhat, A. K., \& Tikoria, J. (2017c) 
Estudantes do campo de negócios

Estudantes de educação física

Estudantes de negócios, engenharia 1 eletrônica e artes

Estudantes de educação social, 1 3,3 pedagogia e serviço social

Estudantes de graduação e mestrado 1 em educação

Estudantes de tecnologia e estudantes de mestrado em negócios internacionais

\begin{tabular}{llll} 
Mestrandos & 1 & 3,3 & Hockerts, K. (2015) \\
\hline Total & 30 & 100 \\
\hline
\end{tabular}

Kedmenec, I., Rebernik, M., \& Tominc, P. (2016)

Hockerts, K. (2017)

Barton, M., Schaefer, R., \& Canavati, S. (2018)

Jahchan, A. L., Comini, G. M., \& D'Amario, E. Q.(2016)

Peris, C. C., Gómez, J. G., Puig, M. M., \& RuizBernardo, P. (2016)

3,3 Perić, J., \& Delić, A. (2014)

Ferrer i Cervero, V., Cabrera Santacana, O., Alegre Benería, R. M., Montané López, A., Sánchez-Valverde Visus, C., \& Alaiz Chueca, E. (2013)

3,3 Shahverdi, M., Ismail, K., \& Qureshi, M. (2018)

3,3 Greblikaite, J., Sroka, W., \& Gerulaitiene, N. (2016)
$5 \quad 16,8 \quad$ Adelekan, S. A., Williamson, M., \& Atiku, S. O. (2018)

No que concerne a métodos, procedimentos e técnicas adotados no desenvolvimento das pesquisas sobre ensino de empreendedorismo social, observa-se a predominância do uso de levantamento de opinião $(86,2 \%)$, seguido por estudos de casos $(13,8 \%)$, sendo todos os estudos de casos subdivididos em estudos de casos múltiplos. Dentro desses estudos apenas um trabalho que realizou entrevistas em grupo. A predominância desses métodos sugere que o assunto ainda é pouco discutido e ainda está em fase inicial, por isso os estudos ainda possuem caráter de reconhecimento e definição do campo. Vale destacar que em $30 \%$ dos artigos o método não foi classificado pelos autores ou foi maneira diferente das definições aqui apresentadas, o que demandou maior atenção para análise.

Em 93,1\% dos estudos a amostra foi flexível ou por conveniência e em apenas dois artigos $(6,9 \%)$ foi estudada por amostra probabilística aleatória. No que se referem ao perfil da amostra, os estudos foram realizados junto a amostras de estudantes universitários de diversos cursos e países, vinculados a diferentes níveis de ensino (graduação, mestrado e doutorado). Além dessas amostras de estudantes, foram também encontrados estudos com professores universitários.

Os instrumentos de coleta de dados mais utilizados foram questionários $(72,4 \%)$, seguidos de roteiros de entrevista $(10,3 \%)$ e métodos mistos $(22 \%)$. Quatro estudos utilizaram pesquisa documental $(13,8 \%)$.

Observou-se que a coleta presencial foi a mais utilizada $(58,6 \%)$, a coleta por meio eletrônico representou $24,1 \%$ e a coleta mista representou $13,8 \%$ do tipo de coleta. Notou-se também um artigo que não informou o meio utilizado na coleta de dados $(3,4 \%)$.

No que se refere às estratégias de análises de dados, as análises estatísticas descritivas e inferenciais foram as mais utilizadas $(41,4 \%)$; seguidas por estudos que utilizaram mais de 
um método de análise de dados $(37,9 \%)$ e por quatro $(13,4 \%)$ estudos que utilizaram análise de conteúdo e apenas dois $(6,7 \%)$ que utilizaram análise temática. Cabe ressaltar que, para a realização da análise temática, um autor citou como referência Braun et al., (2012) e o outro, Flick (2002) e Miles e Huberman (1994).

No que tange a estatísticas descritivas e inferenciais os métodos utilizados foram; Analise fatorial (confirmatória e exploratória), regressão (multivariada e múltipla), análise de correlação, teste t de amostras independentes e pareadas, estatísticas descritivas (média, desvio padrão, frequência), teste de correlação de person, teste qui-quadrado, analise de componentes principais e modelagem de equações estruturais.

\section{Resultado das pesquisas sobre ensino de empreendedorismo social}

A pesquisa em ensino de empreendedorismo social tem ocorrido por meio de disciplinas presenciais e virtuais, programas, competições com a participação de estudantes e professores e outras pessoas. Existem relativamente poucos estudos sobre os efeitos do ensino universitário sobre o comportamento dos estudantes e suas intenções de realizar um empreendimento social. Há, entretanto, uma predominância de estudos sobre intenção empreendedora social, área essa que vem do empreendedorismo tradicional e está sendo adaptada para o empreendedorismo social. Entre eles estão os estudos de Hsu e Wang. (2018) e Ip, Liang et al. (2018), que compararam estudantes universitários de Taiwan e Hong Kong e encontraram diferenças entre os universitários em relação aos traços de personalidade e antecedentes da intenção empreendedora social, respectivamente. No estudo Hsu e Wang. (2018) foi encontrada diferença entre os estudantes em relação a todos os fatores pesquisados dos traços de personalidade, exceto agradabilidade, e no estudo de Ip, Liang et al. (2018) as principais diferenças entre os estudantes foram os efeitos gerados pela experiência anterior, empatia, autoeficácia, percepção de suporte social e utilidade.

Apesar de existirem diferenças entre as amostras pesquisadas, algumas variáveis têm sido analisadas em diversos contextos e os resultados encontrados semelhantes, indicando que elas influenciam a intenção empreendedora social, a saber, quais são: autoeficácia (Konakll, 2015; Tiwari et al., 2017; Hockerts, 2017; Shahverdi et al., 2018; Lacap et al., 2018 Tiwari et al., 2017c), controle comportamental percebido (Tiwari et al., 2017a; Tiwari et al., 2017b; Tiwari et al., 2017c), criatividade (Tiwari et al., 2017a; Tiwari et al., 2017c), educação (Hockerts, 2017; Adelekan et al., 2018; Shahverdi et al., 2018; Hockerts, 2018; Barton et al., 2018), experiência anterior (Kedmenec et al., 2016; Ip, Ling et al., 2018; Hockerts et al., 2017; Lacap et al. 2018; Barton et al., 2018), normas subjetivas (Tiwari et al., 2017a; Tiwari et al., 2017b; Tiwari et al., 2017c), Suporte social (Ip, Ling et al., 2018; Hockerts, 2017; Shahverdi et al., 2018; Lacap et al. 2018). Porém, quanto às variáveis obrigação moral e empatia, foram encontrados resultados divergentes entre as pesquisas.

No que se refere à variável gênero alguns estudos apontam como as mulheres sendo mais propensas ao empreendedorismo social do que os homens (Kedmenec et al. 2016). Hockerts (2017) encontrou níveis mais baixos de empatia em pessoas do sexo masculino em comparação com as do sexo feminino, porém Tiwari et al. (2017b) não encontrou diferença em relação a gênero com a intenção de empreendedorismo social, sugerido assim, que sejam realizados mais estudos que busquem identificar as diferenças entre essas variáveis.

No que tange à educação, Hockerts (2018) concluiu que a educação para o empreendedorismo social tem um impacto positivo na intenção do aluno de iniciar um empreendimento social, bem como sobre a sua autoeficácia e percepção de suporte social. Os 
resultados da pesquisa de Adelekan et al. (2018) confirmaram essa afirmação, ao indicarem uma relação positiva significativa entre conteúdos pedagógicos, técnicas pedagógicas e atitudes dos alunos em direção ao empreendedorismo social. Como resultado, identifica-se que há suporte para a sugestão de Smith e Woodworth (2012) de que a educação para o empreendedorismo social pode ajudar os alunos a desenvolverem a autoeficácia empreendedora social.

O estudo de Kedmenec et al. (2016) encontrou que dos métodos examinados de ensinar empreendedorismo social, aprender a teoria do empreendedorismo social e a análise de empreendimentos sociais são os mais comuns, seguidos por elaboração de planos de negócios para empreendimentos sociais e a participação dos estudantes em palestras proferidas por empreendedores sociais. Finalmente, o menos representado componente da educação para o empreendedorismo social esta levar o estudante para trabalhar em uma empresa social e apoiá-lo a lançar um empreendimento social.

De acordo com Yann et al. (2014) Sabbaghi e Cavanagh, (2018), métodos experienciais produzem benefícios consideráveis para a aprendizagem empreendedora. Isso também reforça a afirmação de Chang et al (2014) de que o ensino experiencial em empresas sociais afeta as características do aluno, assim como a estratégia de ensino de elaboração de planos de negócios afeta positivamente as intenções dos estudantes de iniciar um empreendimento social (Kwong et al., 2012).

Hockerts afirma que disciplinas eletivas de empreendedorismo social têm um efeito positivo em todas as cinco variáveis (empatia, percepção moral, autoeficacia, percepção de suporte social e intenção empreendedora social). No entanto, esses efeitos são fracos e estatisticamente não significativos para a empatia e obrigação moral.

Segundo o estudo de Huster et al. (2017), os alunos que participam de competições de empreendedorismo social são motivados pelo prestígio da competição trabalharem em rede, receberem orientações e treinamento, sendo a mentoria um dos fatores mais importantes da competição, mais do que a própria premiação. Os participantes de cursos de empreendedorismo social também valorizam a diversidade disciplinar e oportunidades de aprendizagem oferecidas pela competição. No que tange às habilidades adquiridas com a participação na competição foram relatadas as principais, como: habilidade de vender sua idéia/negócio (pitch), faltar em público, habilidades de apresentação, captação de recursos, negociação e colaboração. Outros benefícios do ensino de ES para os estudantes referidos pelos estudos foram: aumento da confiança, ampliação de visão de mundo e de perspectivas de liderança que lhes permitiriam ter sucesso em suas carreiras. Os resultados indicaram que a participação no curso aumentou o compromisso com ferramentas de impacto social e que os aprendizados e experiências que ocorreram durante a competição ajudaram os participantes a se tornarem empreendedores sociais globais mais comprometidos, aperfeiçoarem suas habilidades de relacionamento intercultural, bem como suas habilidades de avaliação de impacto social, além de melhorarem a compreensão e a habilidade para quantificar o retorno social, e/ou influenciarem o seu pensamento e trajetória de carreira.

Nos estudos de Perić e Delić (2014), Greblikaite et al. (2016), Jahchan et al. (2016) os alunos abrangidos nunca haviam ouvido falar do conceito de empreendedorismo social e pensavam que não existiam exemplos práticos de empreendedorismo social. Eles associam o empreendedorismo social ao trabalho de organizações sem fins lucrativos e à responsabilidade social corporativa. Predominantemente, argumentam que o empreendedorismo social pode ter alguma influência na resolução de problemas sociais, mas não pode ser a solução para os 
problemas que o país enfrenta. Algumas das questões que podem ser abordadas pelo empreendedorismo social, de acordo com os resultados da pesquisa são: desemprego, gerar valor social ao invés de lucro, educação. Os estudantes consideram o empreendedorismo social importante para o seu currículo (Archibald et al.,2016; Ferrer et al., 2013).

A pesquisa de Mueller et al. (2015) teve o objetivo identificar as motivações estudantis para preferir o empreendedorismo social em detrimento do empreendedorismo tradicional e os resultados indicam claramente que os alunos inclinados para o empreendedorismo social forneceram razões diferentes daquelas apresentados pelos que se inclinavam para o empreendedorismo tradicional. As razões tipicamente mencionadas pelos estudantes que preferiam o ES pertenciam às categorias de impacto, motivação pessoal e considerando aspectos sociais e econômicos, enquanto as razões tipicamente mencionadas pelos alunos que preferiam o empreendedorismo tradicional estavam nas categorias de resultado monetário, oportunidade, viabilidade e filantropia. Cabe ressaltar que, ao contrário do que se acreditava,os estudantes com foco no empreendedorismo tradicional também se preocupam com ações sociais, porém esse não é o seu objetivo principal.

\section{Síntese das Recomendações para educação, lacunas e agenda}

Nesta seção são apresentadas as principais recomendações para o campo da educação em empreendedorismo social. Na sequência, serão relatadas as principais lacunas e agendas de pesquisas do campo, segundo esta revisão sistemática de literatura.

Umas das recomendações é que as universidades devem incentivar estudantes para que eles se envolvam também em atividades de voluntariado, especialmente em atividades para reconhecer que muitas organizações poderiam se beneficiar diretamente de seus conhecimentos e habilidades, isso também é uma forma dos alunos colocarem em prática os conteúdos aprendidos em sala de aula e de participarem de experiências que possibilitam aumentar a autoeficácia dos estudantes (Kedmenec et al., 2016).

No que tange a autoeficácia, Smith e Woodworth (2012) propõem que, para desenvolver o empreendedorismo social, é preciso desenvolvê-la. Estratégias educacionais apropriadas para melhorar a autoeficácia podem incluir o estabelecimento de atividades desafiadoras, e adequadas aos conhecimentos dos aprendizes, de modo que os estudantes possam ter expectativas de sucesso na aprendizagem do empreendedorismo social; fornecimento de feedbacks explícitos, demonstração de confiança nos alunos, reconhecimento e elogios aos esforços de aprendizagem. Semelhante à obrigação moral, os efeitos da autoeficácia vieram principalmente do poder mediador da criatividade empreendedora (Rego Rego, Sousa, Marques, \& Cunha, 2012; Zhou \& Hoever, 2014); esta constatação implica que as estratégias supracitadas devem ser executadas em conjunto com atividades de aprendizagem que promovam a criatividade, a novidade e a flexibilidade empreendedora. Smith e Woodworth (2012), por outro lado, sugerem que a educação para o empreendedorismo social pode ajudar os alunos a construírem a autoeficácia empreendedora social, por exemplo, modelando a aprendizagem vicária, usando a persuasão social, e fornecendo experiências de domínio de campo (Smith e Woodworth, 2012).

Outras metodologias encontradas nos artigos e sugeridas para o ensino de empreendedorismo social é a educação experiencial e a aprendizagem em serviço, essas podem contribuir para aprendizagem mais efetiva dos alunos e também canalizar a empatia dos alunos para o empreendedorismo social, sendo que as análises das duas dimensões da empatia - cognitiva e afetiva - poderiam inspirar os educadores a reconhecerem os dois tipos 
entre os alunos em suas aulas, e projetar intervenções para elevar as intenções empreendedoras sociais em conformidade com as especificidades dos estudantes (Bacq \& Alt, 2018).

Quando se fala especificamente da aprendizagem em serviço, o ponto de partida mais adequado seria fazer com que os alunos encontrem e escolham seus projetos de aprendizado de serviço de forma independente ou em pequenos grupos. Essa liberdade para os estudantes encontrarem seus próprios projetos tem certas implicações tanto para o desenho didático quanto para a organização do curso. Primeiro, a (aprendizagem), os objetivos do projeto de aprendizagem de serviços têm de ser claros. Estes poderiam, por exemplo, incluir os seguintes aspectos: os alunos devem aplicar critérios para projetos de mudança e serem capazes de categorizar projetos de aprendizagem de serviços próprios e de outros; (b) durante o projeto de aprendizagem em serviço, os estudantes devem avançar ainda mais o modelo da respectiva organização com o objetivo de aumentar o impacto; (c) os estudantes devem se comunicar com pelo menos dois grupos de partes interessadas (ou seja, clientes/usuários, comunidades, investidores). Em segundo lugar, no que diz respeito às restrições organizacionais dos cursos de pré-aprendizagem e projetos de aprendizagem de serviço não podem ser limitados a uma única disciplina de um semestre. Ao dar aos alunos a oportunidade de encontrar seus próprios projetos de aprendizado de serviço, uma disciplina de dois semestres seria necessária para cumprir os objetivos de aprendizagem supracitados. Além da possibilidade de escolher o próprio projeto de aprendizagem em serviço, os estudantes devem ser convidados a preencher um questionário sobre motivos pessoais no início do curso de empreendedorismo social. Além disso, os alunos devem refletir ativamente sobre sua experiência de aprendizagem de serviço (por exemplo, escrevendo um diário de aprendizagem) (Ojastu , Chiu,\& Olsen, 2011; Mueller, Brahm \& Neck, H. 2015).

Os educadores do campo do empreendedorismo social devem se concentrar em melhorar a criatividade dos alunos, organizando diversas oportunidades de trabalho em equipe para que os estudantes possam experimentar processos e resultados da construção em conjunto. Em particular, os educadores devem encorajar os alunos a expressar ideias originais durante a fase inicial e, depois, enfatizar abordagens flexíveis para desencadear ações empreendedoras para a inovação social (Ip, Ling et al., 20118), nutrindo e engajando o espírito empreendedor deles desde cedo para que estes estejam preparados para iniciar negócios capazes de produzir mudanças sociais.

Por fim, as descobertas sugerem que as universidades para melhor atingir os seus objetivos de empreendedorismo social devam centrar-se em atividades para cultivar a percepção de viabilidade e percepção de desejabilidade entre os estudantes para promover mais startups sociais. As descobertas também mostram que é importante expor os alunos à viabilidade de empreendimentos sociais por meio de iniciativas como projetos de aprendizagem de serviços ou experiencial em parceria com programas baseados em necessidades organizacionais que podem ser apoiados por meio de laboratórios ou incubadoras universitárias de negócios, incluindo empreendimentos (Barton et al., 2018). A participação dos alunos nessas atividades oportuniza o desenvolvimento de competências empreendedoras possibilitando que eles possam optar pela carreira no campo do empreendedorismo social e os ajudando a se tornarem atores importantes no processo de tomada de decisão e agentes ativos da mudança social positiva na sociedade (Perić \& Delić, 2014). 


\section{Lacunas e agenda de pesquisa}

Esta seção retrata as agendas de pesquisa formuladas por autores dos artigos analisados nesta revisão de literatura. As agendas mais recorrentes mencionam a necessidade de se estudar os métodos de ensino em empreendedorismo social e, em especial, a aplicação da Aprendizagem Experiencial e a Aprendizagem em Serviço (Chang et al. 2014; Kedmenec et al., 2016; Mueller et al., 2015; Yann et al., 2014; Bacq \& Alt, 2018; Hockerts, 2018; Ashour, 2016; Greblikaite et al., 2016), identificar e relacionar melhor os efeitos das variáveis etnia, idade, sexo, familiaridade com tecnologia, experiência social, experiência de trabalho, normas subjetivas, empatia, antecedentes do valor social, autoeficácia, barreiras da intenção de empreendedorismo social, formação da intenção empreendedora social, traço de personalidade, criatividade, motivação, capital social, efeito do estilo cognitivo (Yann et al., 2014; Tiwari et al., 2017; Tiwari et al., 2017; Tiwari et al., 2017; Hockerts, 2017; Bacq \& Alt, 2018; Shahverdi et al., 2018; Hsu \& Wang, 2018; Ip, Wu et al., 2018; Mueller et al., 2015).

Existe também a necessidade de métodos mais robustos de pesquisa que utilizem pré e pós testes, delineamentos experimentais e quase-experimentais, estudos qualitativos, estudos longitudinais (Othman \& Ab Wahid, 2014; Kedmenec, 2016; Bacq \& Alt, 2018; Hsu e Wang., 2018; Greblikaite et al., 2016) e futuras pesquisas que construam/incluam medidas recolhidas externamente que captam comportamentos/desempenho do empreendedorismo social, e também pesquisas que demonstram o envolvimento real no empreendedorismo social e não apenas a intenção empreendedora social de estudantes universitários (Hockerts, 2015; Bacq \& Alt, 2018).

Também foram mencionadas: (1) a necessidade de mais pesquisas que utilizem vários países, departamentos, contextos, participantes VS não participantes, empreendedores sociais VS empreendedores tradicionais (Tiwari et al., 2017; Shahverdi et al., 2018; Hockerts, 2018; Hsu \& Wang., 2018; Greblikaite et al., 2016; Mueller et al., 2015 Lacap et al., 2018; Barton et al., 2018); (2) a possibilidade de usar a escala desenvolvida por Hockerts (2015) para testar, em estudos longitudinais, se a educação empreendedora social influencia a intenção e o comportamento empreendedor social.

Foram sugeridas mais pesquisas sobre o efeito das abordagens de Aprendizagem Experiencial e a Aprendizagem em Serviço para buscar entender as experiências dos acadêmicos em lidar com esta forma metodológica (alunos e professores), verificando também as visões dos outros interessados (comunidade, organizações e empreendedores sociais), especialmente para descobrir como eles se beneficiam desse tipo de abordagens. (Yann et al., 2014; Chang et al. 2014; Bacq \& Alt, 2018).

\section{Conclusão}

A literatura do ensino em empreendedorismo social ainda pode ser considerada um campo emergente e que necessita de mais aprofundamento teórico e empírico, uma vez que ele ainda se encontra sem uma teoria especifica consolidada, utilizando teorias de outros campos do conhecimento para entender esse fenômeno, em especial, da área do empreendedorismo tradicional. Sabemos ainda que muitas das características do empreendedorismo tradicional estejam também relacionadas ao empreendedorismo social, porém os desafios do empreendedor social são diferentes e talvez mais amplos do que o do empreendedor tradicional, exigindo do empreendedor conhecimentos e habilidades diferentes. Dada a importância do ES para a sociedade, é preciso ampliar as pesquisas para explicar e 
conhecer melhor esse fenômeno, uma vez que a literatura, apesar de ter crescido nos últimos anos, ainda carece de evidências cientificas que comprovem a efetividade das ações e dos programas de ensino de empreendedorismo social em universidades.

Uma das lacunas principais do campo de estudo é a necessidade de pesquisas mais robustas, a exemplo, com recorte longitudinal, uma vez que não foi encontrada nenhuma pesquisa na amostra com esse delineamento e os próprios pesquisadores sugerem esse recorte em futuras pesquisas. Parte disso se explica pelo fato da teoria predominante no campo ser a intenção empreendedora social, uma vez que a teoria afirma que a intenção empreendedora social é um preditor do envolvimento das pessoas com o empreendedorismo social, porém não foram identificados resultados empíricos que confirmem isso e se as pessoas com maior intenção empreendedora social são as que de fato empreendem, sendo este um campo bastante promissor para futuras pesquisas.

Um das abordagens promissoras para a educação empreendedora social é a aplicação das metodologias ativas, por exemplo, Aprendizagem Experiencial (Kolb, 1976) e Aprendizagem de Serviços (Brock e Steiner, 2009). Segundo os resultados de Kedmenec et al. (2016), as disciplinas de empreendedorismo social pouco focam nas experiências práticas dos alunos, sendo essa necessidade suprida pelas duas abordagens supracitadas, pois elas permitem que os alunos vivenciem os problemas reais enfrentados pelos empreendedores sociais e aumentem seus níveis de autoeficácia, empatia, intenção empreendedora social, obrigação moral, suporte social, desejabilidade percebida e percepção de viabilidade do empreendimento, o que os tornariam mais preparados para o mercado de trabalho de maneira geral. As variáveis preditoras da intenção empreendedora que mostraram resultados conclusivos são: autoeficácia, percepção de controle comportamental, criatividade, educação, experiência anterior, normas subjetivas e suporte social, sendo importantes indícios para a educação em empreendedorismo social, junto com o desenvolvimento de vivência prática empreendedora dos alunos.

O desenvolvimento de competências empreendedoras sociais nos alunos permite que estes possam optar pela carreira no campo do empreendedorismo social ou aplicá-las elas em outros contextos, tendo em vista que as competências empreendedoras são requeridas por muitas empresas. Vale ressaltar que outros países têm adotados legislações especifica para reger empresas sociais, reconhecendo o valor que estas têm para sanar os problemas sociais. No Brasil, tramita no Congresso Nacional uma lei (Projeto de Lei do Senado $n^{\circ} 338$, de 2018) que trata especificamente desse tipo de empreendimento. Apesar do crescimento do campo de empreendedorismo social no mundo por meio de ações governamentais e empresárias, o tema no meio acadêmico ainda é pouco explorado e nas universidades os alunos quase não têm contato com o tema.

\section{Rererências}

Adelekan, S. A., Williamson, M., \& Atiku, S. O. (2018). Influence of social entrepreneurship pedagogical initiatives on students' attitudes and behaviours. Journal of Business and Retail Management Research, 12(3).

Archibald, P., Muhammad, O., \& Estreet, A. (2016). Business in social work education: A historically black university's social work entrepreneurship project. Journal of Social Work Education, 52(1), 79-94. 
Ashour, S. (2016). Social and business entrepreneurship as career options for university students in the United Arab Emirates: The drive-preparedness gap. Cogent Education, 3(1), 1234425.

Bacq, S., \& Alt, E. (2018). Feeling capable and valued: A prosocial perspective on the link between empathy and social entrepreneurial intentions. Journal of Business Venturing, 33(3), 333-350.

Barton, M., Schaefer, R., \& Canavati, S. (2018). To be or not to be a social entrepreneur: Motivational drivers amongst American business students. Entrepreneurial Business and Economics Review, 6(1), 9-35.

Brock, D. D., \& Steiner, S. (2009). Social entrepreneurship education: is it achieving the desired aims?. Available at SSRN 1344419.

Chang, J., Benamraoui, A., \& Rieple, A. (2014). Learning-by-doing as an approach to teaching social entrepreneurship. Innovations in education and teaching international, 51(5), 459-471.

Cook, D. J., Mulrow, C. D., \& Haynes, R. B. (1997). Systematic reviews: synthesis of best evidence for clinical decisions. Annals of internal medicine, 126(5), 376-380.

Cordeiro, A., Oliveira, G. D., Renteria, J., \& Guimarães, C. (2007). Revisão sistemática: uma revisão narrativa. Grupo de Estudo de Revisão Sistemática do Rio de Janeiro (GERS-Rio). Rev. Col. Bras. Cir, 34(6).

Creswell, J. W. (2007). tradução Luciana de Oliveira da Rocha.-. Projeto de pesquisa: métodos qualitativo, quantitativo e misto. $2^{a}$ ed. Porto Alegre: Artmed.

Cronin, P., Ryan, F., \& Coughlan, M. (2008). Undertaking a literature review: a stepby-step approach. British journal of nursing, 17(1), 38-43.

Ferrer i Cervero, V., Cabrera Santacana, O., Alegre Benería, R. M., Montané López, A., Sánchez-Valverde Visus, C., \& Alaiz Chueca, E. (2013). El perfil del emprendedor social del estudiantado de los Grados de Educación Social, Pedagogía y Trabajo Social en la Universidad de Barcelona. REIRE. Revista d'Innovació i Recerca en Educació, 2013, vol. 7, num. 1, p. 11-29.

Fowler Jr, F. J. (2011). Pesquisa de Levantamento-4. Penso Editora.

Greblikaite, J., Sroka, W., \& Gerulaitiene, N. (2016). Involving young people in Polish and Lithuanian social enterprises by fostering entrepreneurial skills and abilities as entrepreneurial opportunity at university. Entrepreneurial Business and Economics Review, 4(3), 131.

Hair Jr, J. F., Babin, B., Money, A. H., \& Samouel, P. (2003). Essentials of Business Research Methods: Johns Wiley \& Sons. Inc.: New York, NY, USA.

Hockerts, K. (2015). The social entrepreneurial antecedents scale (SEAS): a validation study. Social Enterprise Journal, 11(3), 260-280.

Hockerts, K. (2017). Determinants of social entrepreneurial intentions. Entrepreneurship Theory and Practice, 41(1), 105-130.

Hockerts, K. (2018). The Effect of Experiential Social Entrepreneurship Education on Intention Formation in Students. Journal of Social Entrepreneurship, 9(3), 234-256.

Hsu, C. Y., \& Wang, S. M. (2018). Social entrepreneurial intentions and its influential factors: A comparison of students in Taiwan and Hong Kong. Innovations in Education and Teaching International, 1-11 
Huster, K., Petrillo, C., O’Malley, G., Glassman, D., Rush, J., \& Wasserheit, J. (2017). Global social entrepreneurship competitions: Incubators for innovations in global health?. Journal of Management Education, 41(2), 249-271.

IBGE. (2018). Pobreza aumenta e atinge 54,8 milhões de pessoas em 2017. Recuperado em 11 de abril, 2019, de https://agenciadenoticias.ibge.gov.br/agencianoticias/2012-agencia-de-noticias/noticias/23299-pobreza-aumenta-e-atinge-54-8-milhoes-depessoas-em-2017.

Ip, C. Y., Liang, C., Wu, S. C., Law, K. M. Y., \& Liu, H. C. (2018). Enhancing social entrepreneurial intentions through entrepreneurial creativity: A comparative study between Taiwan and Hong Kong. Creativity research journal, 30(2), 132-142.

Ip, C. Y., Wu, S. C., Liu, H. C., \& Liang, C. (2018). Social entrepreneurial intentions of students from Hong Kong. The Journal of Entrepreneurship, 27(1), 47-64.

Jahchan, A. L., Comini, G. M., \& D'Amario, E. Q. (2016). Negócios sociais: a percepção, a consciência e o grau de interesse pelo tema para os alunos de graduação em administração. Administração: Ensino e Pesquisa, 17(3), 537-566.

Kedmenec, I., Rebernik, M., \& Tominc, P. (2016). Social Entrepreneurship Education and Its Association with Perceived Desirability and Feasibility of Social Entrepreneurship among Business Students. Croatian Journal of Education: Hrvatski časopis za odgoj $i$ obrazovanje, 18(4), 1035-1065

Kolb, D. A. (1976). Management and the learning process. California management review, 18(3), 21-31.

Konakll, T. (2015). Effects of self-efficacy on social entrepreneurship in education: a correlational research. Research in Education, 94(1), 30-43.

Kwong, C. C., Thompson, P., Cheung, C. W. M., \& Manzoor, H. (2012). The role of environment in fostering conductive entrepreneurial learning: teaching the 'art'of entrepreneurship in boot camps. Journal of General Management, 38(1), 45-71.

Lacap, J. P. G., Mulyaningsih, H. D., \& Ramadani, V. (2018). The mediating effects of social entrepreneurial antecedents on the relationship between prior experience and social entrepreneurial intent: The case of Filipino and Indonesian university students. Journal of Science and Technology Policy Management, 9(3), 329-346.

Miller, T. L., Grimes, M. G., McMullen, J. S., \& Vogus, T. J. (2012). Venturing for others with heart and head: How compassion encourages social entrepreneurship. Academy of management review, 37(4), 616-640.

Mueller, S., Brahm, T., \& Neck, H. (2015). Service learning in social entrepreneurship education: Why students want to become social entrepreneurs and how to address their motives. Journal of Enterprising Culture, 23(03), 357-380.

Ojastu, D., Chiu, R., \& Olsen, P. I. (2011). Cognitive model of entrepreneurship and its reflection in education. Journal of Enterprising Culture, 19(04), 397-434.

Othman, N., \& Ab Wahid, H. (2014). Social entrepreneurship among participants in the students in free enterprise program. Education+ Training, 56(8/9), 852-869.

Perić, J., \& Delić, A. (2014). Social entrepreneurship in Croatia: Do regional disparities influence young people's perception of social entrepreneurship as a potential career path?. Ekonomski vjesnik: Review of Contemporary Entrepreneurship, Business, and Economic Issues, 27(1), 81-92. 
Peris, C. C., Gómez, J. G., Puig, M. M., \& Ruiz-Bernardo, P. (2016). The construction of a questionnaire to measure social entrepreneurship in physical education. Pedagogía Social. Revista Interuniversitaria, (28), 169-188.

Sabbaghi, O., \& Cavanagh, SJ, G. F. (2018). Social entrepreneurship and sensemaking: evidence from the Global Social Benefit Institute. Social Enterprise Journal, 14(3), 289-311.

Sen, A. K. (1999). Development as Freedom. New York: Anchor Books

Senado Federal. (1998). Constituição da República Federativa do Brasil de 1988. Recuperado em 11 de abril, 2019, de http://legis.senado.leg.br/legislacao/ListaTextoSigen.action?norma=579494\&id=16434803\&i dBinario $=16434817$.

Senado Federal. (2018). Projeto de Lei do Senado $n^{\circ} 338$, de 2018. Recuperado em 11 de abril, 2019, de https://www25.senado.leg.br/web/atividade/materias/-/materia/133946

Shadish, W. R., Cook, T. D., \& Campbell, D. T. (2002). Experimental and quasiexperimental designs for generalized causal inference. Boston, MA: Houghton Mifflin

Shahverdi, M., Ismail, K., \& Qureshi, M. (2018). The effect of perceived barriers on social entrepreneurship intention in Malaysian universities: The moderating role of education. Management Science Letters, 8(5), 341-352.

Smith, B.R., Kickul, J. and Coley, L. (2010), "Using simulation to develop empathy and motivate agency: an innovative pedagogical approach for social entrepreneurship education", Handbook of Research in Entrepreneurship Education, pp. 13-24.

Smith, I. H., \& Woodworth, W. P. (2012). Developing social entrepreneurs and social innovators: A social identity and self-efficacy approach. Academy of Management Learning \& Education, 11(3), 390-407.

Tams, S., \& Marshall, J. (2011). Responsible careers: Systemic reflexivity in shifting landscapes. Human Relations, 64(1), 109-131.

Tiwari, P., Bhat, A. K., \& Tikoria, J. (2017a). An empirical analysis of the factors affecting social entrepreneurial intentions. Journal of Global Entrepreneurship Research, 7(1), 9.

Tiwari, P., Bhat, A. K., \& Tikoria, J. (2017b). Predictors of social entrepreneurial intention: an empirical study. South Asian Journal of Business Studies, 6(1), 53-79.

Tiwari, P., Bhat, A. K., \& Tikoria, J. (2017c). The role of emotional intelligence and self-efficacy on social entrepreneurial attitudes and social entrepreneurial intentions. Journal of Social Entrepreneurship, 8(2), 165-185.

Thomsen, B., Muurlink, O., \& Best, T. (2018). The political ecology of universitybased social entrepreneurship ecosystems. Journal of Enterprising Communities: People and Places in the Global Economy, 12(2), 199-219.

Yann Ching Chang, J., Benamraoui, A., \& Rieple, A. (2014). Stimulating learning about social entrepreneurship through income generation projects. International Journal of Entrepreneurial Behavior \& Research, 20(5), 417-437.

Yin, R. K. (2002). Estudo de caso: planejamento e métodos. Porto Alegre: Artmed.

Zhou, J., \& Hoever, I. J. (2014). Research on workplace creativity: A review and redirection. Annu. Rev. Organ. Psychol. Organ. Behav., 1(1), 333-359. 